\title{
Introducing oral pre-exposure prophylaxis to adolescent girls and young women in Tanzania: Overview of findings from implementation science research
}

Population Council

Follow this and additional works at: https://knowledgecommons.popcouncil.org/departments_sbsr-hiv

Part of the Demography, Population, and Ecology Commons, Family, Life Course, and Society Commons, International Public Health Commons, Medicine and Health Commons, and the Women's Health Commons How does access to this work benefit you? Let us know!

\section{Recommended Citation}

Population Council. 2017. "Introducing oral pre-exposure prophylaxis to adolescent girls and young women in Tanzania: Overview of findings from implementation science research," DREAMS Tanzania Results Summary Brief. Washington, DC: Population Council. 


\section{INTRODUCING ORAL PRE-EXPOSURE PROPHYLAXIS TO ADOLESCENT GIRLS AND YOUNG WOMEN IN TANZANIA: OVERVIEW OF FINDINGS FROM IMPLEMENTATION SCIENCE RESEARCH}

Policymakers and other key stakeholders in Tanzania are currently considering making oral pre-exposure prophylaxis (PrEP) available as an HIV prevention option for adolescent girls and young women (AGYW) and other vulnerable populations. PrEP is an antiretroviral medication taken by HIV-uninfected persons to prevent HIV.

The Population Council in collaboration with the National AIDS Control Program (NACP) and CSK Research Solutions Limited conducted implementation science research in one urban district (Dar es Salaam) and one rural district (Mbeya) to provide needed evidence for informing decision-making on whether and how to introduce PrEP to AGYW in Tanzania. The aims of the research were to:

- Assess the acceptability of PrEP among AGYW, their male partners, their parents/guardians, healthcare providers (HCPs), and policymakers.

- Determine the feasibility of and opportunities for providing PrEP to AGYW.

- Identify key facilitators and barriers to PrEP introduction to AGYW.

\section{KEY FINDINGS AND CONSIDERATIONS FOR PREP INTRODUCTION}

- Need for PrEP: All study participants agreed that AGYW need PrEP due to existing socio-cultural circumstances that increase their risk of HIV. Specifically, participants described a lack of trust in sexual relationships; limited or inconsistent condom use; restrictive gender norms that prohibit women, particularly young women, from refusing sexual intercourse with their partners; and women's experiences of sexual violence as important reasons for AGYW having access to PrEP.

- Fear of stigma: Because PrEP is an ARV, all participant groups were concerned that individuals taking PrEP would be seen as being HIV positive and therefore, the existing stigma and discrimination toward people living with HIV could apply to them, as well. Additionally, AGYW who take PrEP might be labeled as promiscuous. Of importance in reducing stigma was appropriate community education and sensitization about PrEP, and ensuring that PrEP delivery was integrated into preventive health services rather than offered at HIV care and treatment centers.

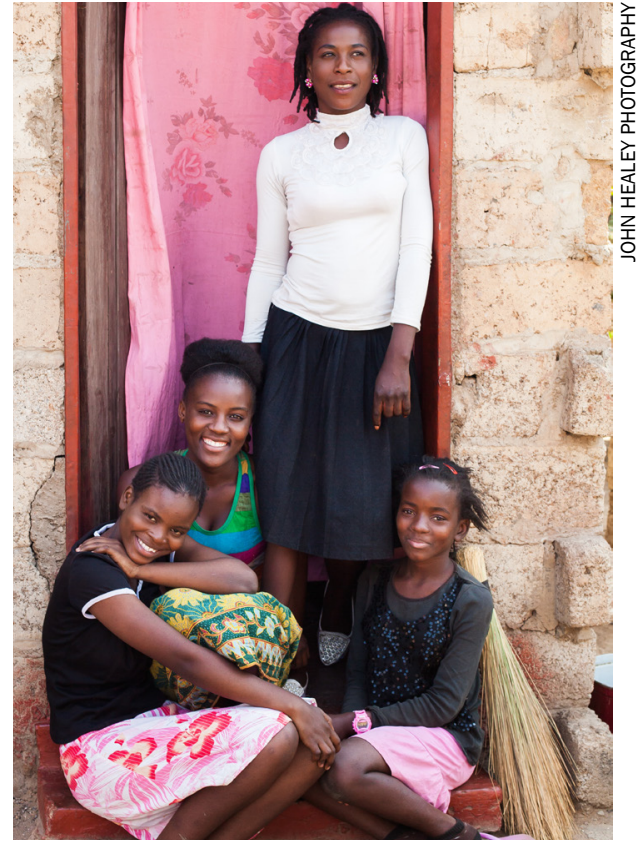

Countries will need to develop a vision for how PrEP for AGYW fits into their overall HIV prevention landscape and how to address challenges associated with its introduction.

Research Partners: CSK Research Solutions Ltd \& National AIDS Control Program (NACP)

Collaborators: PEPFAR/Tanzania \& Sauti/Tanzania

Funder: Bill \& Melinda Gates Foundation

Location: Dar es Salaam and Mbeya Districts

Study Duration: 2016-2018 
- Fertility concerns: AGYW, parents/guardians, and HCPs expressed concerns about the side effects of PrEP. The ability to conceive or fertility desire was the most common concern about the long-term use of PrEP, especially for AGYW who had not yet conceived a child. In addition to education and sensitization of the community, HCPs must be adequately trained to counsel and address questions raised by potential PrEP clients.

- Affordability and financing of PrEP: AGYW, HCPs, and policymakers had concerns about the affordability of PrEP. AGYW and HCPs were concerned about the cost to the end-user; if it was high, this could be a prohibitive factor in choosing to use PrEP. Policymakers, on the other hand, were concerned about the long-term financing of PrEP for Tanzania given that the country is dependent on development partners to fund the its HIV program. A plan for long-term financing of PrEP that takes into account the end-user and the country's financial situation should be created, in collaboration with key national and international stakeholders.

\section{- Early engagement of partners in decision-making:} AGYW and male partners of AGYW stated that male partners will support PrEP use by AGYW but the support is dependent on the men receiving appropriate education on PrEP and including them in the decisionmaking process. If AGYW did not engage their male partners or covertly used PrEP, it would be viewed as a severe breach of trust within their relationship. Efforts should be made to engage male partners and couples in PrEP implementation activities for AGYW, including in the design of counseling messages and education campaigns.

\section{- Engagement of parents and guardians: AGYW and} parents/guardians stated that parents/guardians would be willing to support AGYW's use of PrEP but noted parents/guardians would require accurate information and strategies on how they can support and advocate for PrEP use. As such, educating parents and guardians about PrEP and engaging them in implementation activities should be part of PrEP rollout strategies for AGYW.

\section{STUDY SAMPLE DESCRIPTION}

The research team collected data from March to June 2017, using in-depth interviews (IDIs), focus group discussions (FGDs), key informant interviews (KIIs) and surveys.

\begin{tabular}{|c|c|c|c|c|}
\hline \multirow{2}{*}{$\begin{array}{l}\text { \# Participant } \\
\text { category }\end{array}$} & \multicolumn{3}{|c|}{ No. by method per study site } & \multirow{2}{*}{$\begin{array}{c}\text { Total } \\
\text { number of } \\
\text { participants }\end{array}$} \\
\hline & Method & $\begin{array}{l}\text { Dar Es } \\
\text { Salaam }\end{array}$ & Mbeya & \\
\hline \multicolumn{5}{|l|}{1 AGYW } \\
\hline Married & IDI & 6 & 6 & 12 \\
\hline $\begin{array}{l}\text { Female sex } \\
\text { workers }\end{array}$ & IDI & 6 & 6 & 12 \\
\hline Unmarried & FGD & 2 & 2 & 38 \\
\hline $\begin{array}{l}2 \text { Male partners } \\
\text { of AGYW }\end{array}$ & IDI & 8 & 8 & 16 \\
\hline \multicolumn{5}{|l|}{$\begin{array}{l}3 \text { Parents/ } \\
\text { Guardians }\end{array}$} \\
\hline Males & FGD & 2 & 2 & 27 \\
\hline Females & FGD & 2 & 2 & 28 \\
\hline \multicolumn{5}{|l|}{$4 \mathrm{HCPs}$} \\
\hline & IDI & 12 & 12 & 24 \\
\hline & Surveys & 196 & 120 & 316 \\
\hline 5 Policy makers & KII & 10 & 11 & 21 \\
\hline
\end{tabular}

- Preparedness of the health care system: AGYW, HCPs, and policymakers reported that the current health care system could impede PrEP delivery and uptake. AGYW and HCPs noted that adolescents receive poor quality care (e.g., lack of confidentiality, judgmental attitudes) by some providers. They noted that HCPs require continuous training to provide youth-friendly care and counseling to adolescents. Policymakers and HCPs were concerned that the addition of PrEP as a service could be taxing on an already overstretched health system, including increasing provider workloads and increasing congestion at clinics. PrEP implementation strategies should consider collaborating with community-based providers and organizations to minimize the burden on the health care system.

For more information, contact Nanlesta Pilgrim (npilgrim@ popcouncil.org), Lou Apicella (lapicella@popcouncil.org), or Catherine Kahabuka (ckahabuka@cskresearch.com).

\section{POPULATION} COUNCIL

Ideas. Evidence. Impact.
The Population Council confronts critical health and development issues-from stopping the spread of HIV to improving reproductive health and ensuring that young people lead full and productive lives. Through biomedical, social science and public health research in about 50 countries, the Council works with our partners to deliver solutions that lead to more effective policies, programs, and technologies to improve lives worldwide. Established in 1952 and headquartered in New York, the Council is a nongovernmental, nonprofit organization with an international board of trustees. popcouncil.org

Suggested citation: Population Council. 2017. "Introducing oral pre-exposure prophylaxis to adolescent girls and young women in Tanzania: overview of findings from implementation science research,” DREAMS Tanzania Results Summary Brief. Washington, DC: Population Council. 